ARTIGO

\title{
Teoria(s) da atribuição: um quadro explicativo para o rendimento acadêmico
}

Marco Paulo Maia Ferreira' (D)

\section{RESUMO}

O processo atribucional originou uma enorme diversidade de trabalhos teóricos e empíricos nos últimos 60 anos, representando uma área de investigação marcante em vários domínios da prática psicopedagógica. Este artigo apresenta uma revisão histórica, evolutiva e sistemática da literatura acerca do contributo das variáveis sociocognitivo-motivacionais para a aprendizagem, enfatizando a relevância do processo atribucional no rendimento acadêmico.

PALAVRAS-CHAVE

teoria(s) da atribuição; rendimento acadêmico; avaliação atribucional; dimensões causais.

Instituto Superior de Educação de Lisboa, Lisboa, Portugal. 


\section{ATTRIBUTION THEORY(IES): AN EXPLANATORY FRAMEWORK FOR ACADEMIC ACHIEVEMENT}

\section{ABSTRACT}

The attributional process originated an enormous diversity of theoretical and empirical works in the last 60 years, representing an area of research that is remarkable in several domains of psychopedagogical practice. This article presents a historical, evolutionary and systematic review of the literature about the contribution of socio-cognitive-motivational variables to learning, emphasizing the relevance of the attributional process in academic achievement.

\section{KEYWORDS}

attribution theory(ies); academic achievement; attributional assessment; causal dimensions.

\section{TEORIAA(S) DE LA ATRIBUCIONES: UN QUADRO EXPLICATIVO} PARA EL RENDIMIENTO ACADÉMICO

\section{RESUMEN}

El proceso atribucional originó una enorme diversidad de trabajos teóricos y empíricos durante los últimos 60 años, representando un área de investigación importante en diversos ámbitos de la práctica psicopedagógica. Este artículo presenta una revisión histórica, evolutiva y sistemática de la literatura acerca de la contribución de las variables socio-cognitivo-motivacionales para el aprendizaje, enfatizando la relevancia del proceso atribucional en el rendimiento académico.

\section{PALABRAS CLAVE}

teoría(s) de la asignación; rendimiento académico; evaluación atribucional; dimensiones causales. 


\section{INTRODUÇÃO}

Há várias décadas que os psicólogos sociais se interessam pela temática da percepção das pessoas, nomeadamente pela forma como estas explicam o seu comportamento e o dos outros. Esse campo da psicologia social dirigido para os processos de imputação de causalidade convencionou-se chamar de atribuição causal (Sousa, 1996).

Os processos atribucionais deram origem a uma variedade de trabalhos teóricos e empíricos nos últimos 60 anos, representando uma área de investigação marcante em diversos domínios da prática psicopedagógica. Historicamente, a teoria da atribuição surgiu com os trabalhos de Fritz Heider em 1958. Heider (1958) diz que o homem é motivado para descobrir as causas dos eventos e entender o seu ambiente, afirmando que as relações que estabelecemos com o meio ambiente influenciam a forma como nos comportamos no dia a dia.

Atualmente, a investigação sobre a relação entre as características intelectuais e os desempenhos individuais valoriza um conjunto de variáveis pessoais como moderadoras de tal relação. Esses estudos englobam um conjunto de variáveis como as expectativas de locus de controle, o desânimo aprendido, a autoeficácia e as atribuições causais, sendo denominadas no seu conjunto de variáveis sociocognitivo-motivacionais (Marić e Sakač, 2014; Palos et al., 2011).

A pesquisa sobre o contributo das variáveis sociocognitivo-motivacionais para a aprendizagem e cognição salienta a sua importância no nível de rendimento escolar (Barros e Almeida, 1991). Assim, professores e demais técnicos de educação devem tomar em conta a eliminação de situações pautadas pela insegurança de sentimentos, medo do fracasso, cristalização de percepções pessoais negativas ou colocação em ridículo de comportamentos e dificuldades de aprendizagem. Climas de aprendizagem pautados pela aceitação social, autoestima e consideração positiva por parte dos outros (sejam os pares, sejam os adultos) podem potencializar beneficamente os ambientes escolares, tornando-os condicionantes favoráveis da aprendizagem e da realização acadêmica. A carga afetiva e motivacional desses dois polos opostos pode explicar a existência de alunos com padrões de realização orientados para a mestria ou para o fracasso, claramente diferenciados em termos de persistência e envolvimento nas tarefas de aprendizagem (Sousa, 1996; Schunk e Pajares, 2009).

\section{EVOLUÇÃO DA TEORIA DA ATRIBUIÇÃO}

As atribuições causais têm sido alvo de um estudo sistemático e continuado por parte de investigadores de vários quadrantes da psicologia. Contudo, apesar de serem muitos os autores que deram o seu contributo para a formação de uma teoria geral da atribuição, os trabalhos de Heider, de Jones e Davis, de Kelley, de Jones e Nisbett, de Weiner e de Russel são frequentemente reconhecidos como as principais referências nesse campo de investigação (Biddle, 1993; Hewstone, 1989; Ross e Fletcher, 1985). Porém, de acordo com alguns autores, não se deve falar apenas de uma teoria da atribuição, mas, sim, devem considerar-se várias teorias da atribuição (Kelley e Michela, 1980; Ross e Fletcher, 1985; Graham e Williams, 2009). 


\section{HEIDER E A PSICOLOGIA INGÊENUA}

Heider é, unanimemente, considerado o pai da teoria da atribuição. Esse fato deve-se à publicação do seu artigo "Social perception and phenomenal causality", em 1944. Neste texto, apresentou, pela primeira vez, as suas ideias relativamente à atribuição causal, explicando os processos de pensamento que as pessoas utilizam para retirarem sentido dos acontecimentos quotidianos que ocorrem no mundo que as rodeia. Mais tarde, destacou, igualmente, a importância de os psicólogos compreenderem a psicologia do senso comum, a psicologia ingênua (Heider, 1958). Para Heider, existe semelhança entre os processos utilizados pelos cientistas e os usados pelo homem comum para explicar os acontecimentos, havendo elementos subjetivos que guiam a percepção das pessoas sobre os outros ou sobre si mesmas. $\mathrm{O}$ homem tem necessidade de descobrir as causas dos acontecimentos e de entender o ambiente que o rodeia (Heider, 1958).

A ideia-base de Heider é a de que as pessoas não observam nem armazenam mentalmente sucessos e comportamentos como se de autômatos se tratassem, mas analisam-nos para entender as suas causas (Ross e Fletcher, 1985).

Heider (1958) centra a sua análise na forma como os indivíduos ajustam internamente as suas cognições de maneira a estarem em equilíbrio consigo próprios e nos ajustamentos que eles mesmos fazem perante o meio social onde se inserem. O psicólogo acreditava que o comportamento era o resultado da interação entre fatores pessoais ou internos (aptidão, esforço, fadiga) e fatores ambientais ou externos (dificuldade da tarefa, oportunidade, sorte) (Heider, 1958). Logo, era a percepção das relações entre esses dois fatores que condicionaria o indivíduo, que faria a atribuição, a selecionar o seu comportamento. Ao compreendermos uma ação como resultado de fatores pessoais, estamos a fazer uma atribuição de causalidade interna. Se, pelo contrário, atribuímos a ocorrência como resultado de fatores externos, sobre os quais não temos controle, estamos a fazer uma atribuição de causalidade externa (Barros, 1992).

Hewstone e Fincham (1996) afirmam que essa divisão de Heider sobre as potenciais fontes de realização de uma ação, considerando umas como relativas à pessoa (internas) e outras como relativas ao meio ambiente (externas), foi provavelmente a sua principal contribuição para a edificação da teoria da atribuição.

Para Heider (1958), a atribuição de invariâncias a objetos e eventos torna possível um mundo mais ou menos estável, previsível e controlável. Heider (1958) constatou que se verifica nas pessoas, de modo geral, predisposição para a realização de atribuições a causas estáveis. Essa estabilidade representa para o indivíduo melhor controle sobre o ambiente que o rodeia e mais capacidade de antecipação do comportamento dos outros. Segundo o mesmo autor, as pessoas tentam encontrar condições invariantes que as ajudam a explicar o que se passa à sua volta.

Hewstone (1989) afirma que o sujeito assume a responsabilidade pela sua conduta, quando:

- conhece, ou pode prever, as consequências do seu comportamento;

- tem capacidade para realizar aquele comportamento ou ação, isto é, quando o seu comportamento é intencional e não resulta de um acaso. 
Heider (1958) postula, igualmente, a existência de uma relação entre capacidade e esforço. Se um desses elementos for nulo, a força dos fatores pessoais por si só não explica o efeito. Nesse caso, ele é explicado em termos dos fatores situacionais. Assume-se, também, relação direta entre a dificuldade da tarefa e do esforço. Ou seja, um elevado grau de dificuldade da tarefa tem de ser acompanhado de um nível elevado de esforço para que determinado resultado seja atingido. $\mathrm{O}$ esforço aparece, assim, como uma função da vontade de, ou motivação para.

Os trabalhos de Heider, cujas ideias principais constam do seu livro The psychology of interpersonal relations, editado em 1958, continuam a ser um marco fundamental e fonte valiosa de conhecimento relativo à atribuição causal (Sousa, 1996; Vala, 1991).

\section{JONES E DAVIS E AS INFERÊNCIAS CORRESPONDENTES}

Após Heider, na linha das atribuições causais, surgem os trabalhos de Jones e Davis (1965), que apresentaram um modelo centrado nas atribuições disposicionais para explicar o processamento da informação e inferências correspondentes. Esse modelo tenta esclarecer o modo como as pessoas inferem características disposicionais ou de personalidade, recorrendo somente ao comportamento apresentado/ observado. Segundo esses autores, o sucesso na inferência de traços e intenções verificados nos outros é visto como resultado da atenção prestada a aspectos fundamentais do seu comportamento.

Jones e Davis (1965) apontam critérios que servem de base para que façamos inferências correspondentes, ou seja, que a relação entre o ato observado e a disposição subjacente que o motivou fique mais nítida:

- $1^{\circ}$ critério: princípio do efeito não-comum, ou seja, quanto menor o número de causas possíveis para um evento, maior a possibilidade de acerto nas inferências. Por exemplo, quando uma pessoa, ao ser apresentada a outra, diz "muito prazer", pode estar a expressar um sentimento real ou a obedecer a uma regra social. $\mathrm{O}$ fato de haver duas possibilidades causais comuns dificulta a inferência da verdadeira disposição do autor do evento;

- $2^{\circ}$ critério: princípio da relevância hedônica. É a possibilidade que a ação de uma pessoa tem de gerar consequências boas ou más na perspectiva de um observador. Ao dizer "muito prazer", o indivíduo pode obter aceitação ou evitar a reprovação social. Quanto maior a relevância hedônica, mais correspondente é a inferência do observador acerca do comportamento de uma pessoa;

- $3^{\circ}$ critério: princípio do personalismo. Traduz-se pela relevância da presença de uma pessoa para o comportamento de outra. Quando o comportamento de uma pessoa é dirigido a outra, esta tem mais possibilidade de fazer inferências correspondentes sobre a disposição dessa pessoa do que se a ação não tivesse sido desencadeada pela sua presença.

O modelo das inferências correspondentes proposto por Jones e Davis (1965) contribuiu para a compreensão do fenômeno atributivo e representa um esforço no 
sentido de se obter mais clarificação das ideias iniciadas por Heider. Esse modelo representa a importância das opções disponíveis para o indivíduo, especifica variações de processos que vão condicionar a força das atribuições e providencia um modelo mais testável do que o de Heider (Ross e Fletcher, 1985).

O modelo de Jones e Davis concebe o atribuidor causal como um utilizador de crenças sociais sobre a probabilidade de emergência de comportamentos observados, racional nas suas opções exceto quando o comportamento notado interfere nas suas necessidades epistêmicas (Sousa, 1996; Gawronski, 2004). No entanto, ao substantivar que a intenção é necessária para a inferência de atributos de personalidade, negligencia atributos que se caracterizam precisamente pela ausência de intenção. Para além disso, ao centrar-se nos ganhos informacionais, esse modelo relega para segundo plano a componente afetiva dos comportamentos presente em Heider (Sousa, 1996).

\section{KELLEY, O PROCESSAMENTO DA INFORMAÇÃO E O ESQUEMA CAUSAL}

O contributo de Kelley para o campo da atribuição é o corolário lógico duma abordagem racionalista no âmbito da atribuição, valorizando as escolhas lógicas e racionais das pessoas (Sousa, 1996). Enquanto o modelo de Jones e Davis (1965) destaca as inferências subjetivas, Kelley $(1967 ; 1973)$ optou por desenvolver o princípio da covariação. Os conceitos-base para a conceptualização das relações interpessoais são as pessoas, o cenário e a situação. O procedimento do percipiente baseia-se no princípio da covariação entre as causas e os efeitos possíveis (Kelley e Michela, 1980).

Kelley (1967) afirma que as pessoas atribuem uma causa a uma situação, processando informação sobre a variação, situacional ou não, das condições e circunstâncias que acompanham a situação. Assim, se um evento ocorre sempre na presença de algo, atribui-se a esse algo a causa do evento. Por exemplo, se, todas as vezes que me constipei, estava frio, atribuo ao frio o surgimento da constipação. O mesmo autor evoca três princípios importantes na análise de um comportamento: a distintividade, a consistência ou constância e o consenso.

A consistência refere-se ao conhecimento que o percipiente tem acerca da história do comportamento do ator. Ela é considerada elevada quando uma pessoa revela o mesmo comportamento em diferentes ocasiões. Ou seja, se, sempre que o estímulo estiver presente, a pessoa produz um comportamento igual ou semelhante, mesmo que possa variar a forma de interação com o estímulo (consistência no tempo e na modalidade). Por exemplo, quando alguém grita ou demonstra medo sempre que vê uma cobra ou quando observa fotografias de cobras. Quando o comportamento ocorre de forma intermitente perante o mesmo estímulo, a consistência considera-se baixa (Kelley, 1967).

A distintividade refere-se à forma como o ator se relaciona com outras entidades. Consiste na perceção de que determinado comportamento é emitido pela pessoa perante qualquer estímulo ou apenas quando está presente um estímulo específico. Se o comportamento aparece apenas quando um estímulo específico está presente, diz-se que esse comportamento tem alta distintividade; caso contrário, o comportamento tem baixa distintividade (Kelley, 1967). 
O consenso diz respeito à forma como outros atores reagem à entidade em questão. Ele é considerado alto se várias pessoas agem de maneira semelhante perante o mesmo estímulo; caso contrário, o consenso é considerado baixo (Kelley, 1967).

Kelley (1967) diz-nos que, quando o comportamento de uma pessoa diante de um estímulo possui baixa distintividade, baixa consistência e baixo consenso, tendemos a atribuir o comportamento a causas específicas da pessoa (atribuição interna); quando possui alta distintividade, alta consistência e alto consenso, tendemos a atribuir causas referentes a aspectos característicos da entidade em si (atribuição externa).

Os princípios propostos por Kelley auxiliam no processo de diferenciar causas derivadas do ambiente (externas) das derivadas do sujeito (internas), contudo a falta de elementos e dados sobre distintividade, consistência e consenso dificulta a aplicação do princípio de covariação (Barros, Barros e Monteiro Neto, 1993).

Mais tarde, Kelley (1972) propôs um mecanismo orientado para a estrutura do raciocínio causal - o esquema causal. Entende-se por esquema causal uma estrutura cognitiva que representa relações de causa-efeito, previamente armazenadas em memória, ou, dito de outra forma, crenças causais (Sousa, 1996; Malle, 2011). A noção de esquema causal permitiu a Kelley (1972) definir dois mecanismos com fortes implicações para a atribuição causal, os princípios do desconto e do aumento:

- o princípio do desconto consiste no fato de descontarmos o papel de outras possíveis causas de um evento quando uma delas se destaca como a provável. Por exemplo, um advogado que recebeu dinheiro para defender um traficante de droga. Infere-se que o dinheiro (recompensa) é a causa do evento, descontando outras possíveis causas. O grau de confiança com que a inferência é feita diminui se outras causas plausíveis para o efeito puderem ser consideradas;

- o princípio do aumento diz respeito a situações de julgamento em que existem múltiplas causas prováveis e em que uma facilita a emergência do efeito enquanto outra o inibe. Esse princípio ocorre quando o indivíduo enfrenta custos e dificuldades para emitir determinado comportamento. Assim, a nossa atribuição tende a ser de causas internas. $\mathrm{O}$ esforço despendido para enfrentar obstáculos aumenta a percepção de causalidade interna.

Kelley (1972), citado por Sousa (1996), afirma que, quando o sujeito acredita que o comportamento observado é a consequência de determinada configuração de fatores necessários para que o efeito ocorra, ele está a basear-se num esquema de causalidade múltipla e necessária. Por outro lado, quando raciocina em termos de que cada uma das diferentes causas envolvidas é suficiente para desencadear o comportamento (apesar de outras causas estarem associadas), o sujeito está a utilizar um esquema de causalidade múltiplo, mas suficiente. Por último, quando o raciocínio é o de que a situação envolve o efeito aditivo de um conjunto de causas responsável pela força com que ele se manifesta, o sujeito está a basear-se num esquema de causas compensatórias. 
A introdução da ideia de esquema causal sugere que o sujeito pode se basear em crenças e expectativas sobre covariação de causas e efeitos. A capacidade de detecção de covariação é limitada no ser humano (Ross e Fletcher, 1985).

As matrizes sociais fornecem elas próprias aos seus membros um conjunto de crenças sobre o funcionamento em sociedade e sobre as relações causais existentes. Kelley sugere que as primeiras decisões em matéria de imputação de causalidade são determinantes na estruturação do conhecimento do percipiente na medida em que condicionam decisões posteriores nessa matéria (Kelley e Michela, 1980).

$\mathrm{O}$ trabalho de Kelley no âmbito da atribuição visa o raciocínio refletido e lógico do sujeito, sendo limitativo no que diz respeito à articulação entre emoções, fatores motivacionais e processos lógico-racionais de imputação de causalidade (Sousa, 1996). Comparativamente a Jones e Davis, é possível afirmar que, em Kelley, a base de dados do sujeito é função da experiência prévia, podendo ocorrer distorções por conta da interferência das crenças do próprio sujeito (Kelley e Michela, 1980; Malle, 2011).

\section{JONES E NISBETT E A DIVERGÊNCIA DE PERSPETIVAS ENTRE ATOR E OBSERVADOR}

Jones e Nisbett são autores muito referenciados no campo da atribuição, tendo centrado a sua atenção nas razões para a divergência de perspectivas entre ator e observador. Atores e observadores de uma ação são influenciados por um viés ou tendenciosidade divergente nas suas atribuições. Os atores, ao analisarem o seu comportamento, percebem-no como uma resposta adaptativa às forças situacionais, tendem a fazer atribuições situacionais (externas), enquanto os observadores de uma ação tendem a fazer atribuições disposicionais (internas ao ator), inferindo as causas do comportamento do ator em função das suas características pessoais (Jones e Nisbett, 1972). Assim, quando observamos o comportamento dos outros, tendemos a atribuir-lhes causalidade pessoal; ao analisarmos o nosso próprio comportamento, atribuímos o seu aparecimento mais a causas externas. Para os autores, essa tendenciosidade divergente entre atores e observadores decorre da diferença de informações que possuem. $\mathrm{O}$ ator tem mais acesso a informações relativas ao seu comportamento passado em situações semelhantes, o que lhe permite pesar melhor a influência de causas externas no seu comportamento específico (Malle, 2006).

Segundo Rodrigues (1984), a baixa distintividade e a baixa consistência (terminologia de Kelley, 1967) fazem com que o ator enfatize atribuições externas. O observador, por falta desse conhecimento, tende a atribuir disposições internas para o comportamento da pessoa observada. Como também, do ponto de vista do observador, o comportamento da pessoa é a característica mais saliente, há a tendência em atribuí-lo à pessoa observada (atribuição interna).

Segundo Rodrigues $(1980 ; 1984)$, independentemente das razões propostas para explicar a hipótese das perspectivas divergentes, há muitas evidências empíricas comprovando as ideias de Jones e Nisbett. Outra distinção importante foi introduzida por Cunningham, Starr e Kanouse (1979). Esses autores diferenciaram o papel ativo ou passivo do observador, tendo chegado à conclusão de que os observadores ativos tendem a ter perspectivas convergentes com as do ator em termos do peso dos fatores pessoais e divergentes dos observadores passivos. Isso reforça o papel moderador do 
envolvimento na situação. A perspectiva é, basicamente, a de que, se os indivíduos tiverem acesso aos mesmos dados, isto é, à mesma informação, não deverão apresentar diferenças ao nível atribucional (Cunningham, Starr e Kanouse, 1979).

\section{LOCUS DE CONTROLE DE ROTTER E LOCUS DE CAUSALIDADE DE WEINER}

Apesar de não ser um teórico da teoria da atribuição, os postulados sobre controle externo de Rotter entrecruzam-se com a teoria da atribuição e provocaram reflexões em muitos autores (Weiner et al., 1971; Abramson, Seligman e Teasdale, 1978; Monroe e Malle, 2010), gerando confusões conceptuais entre as atribuições causais e as expectativas de controle interno / externo dos reforços.

Em 1966, Rotter definiu locus de controle como a expectativa generalizada de alguém com capacidade de controlar os acontecimentos (reforços) no seguimento das suas ações, alterando, dessa forma, a expectativa generalizada de resultados positivos ou negativos. O locus de controle é interno se o indivíduo percebe os resultados como consequência das suas próprias ações, e externo se é consequência de fatores situacionais. Assim, os indivíduos apresentam um locus de controle interno se pensam que podem exercer algum controle sobre o que lhes acontece; e externos se acreditam que esse controle não depende deles. Essa disposição (ou orientação) interna ou externa interfere no desempenho dos indivíduos (Rotter, 1966).

Dessa forma, locus de controle é um conceito anterior às atribuições causais; refere-se às expectativas que o indivíduo possui antes de um evento e, portanto, não é um constructo da teoria da atribuição. Ocorre, porém, que, para Rotter (1966), o indivíduo interpreta os acontecimentos, atribuindo-lhe causalidade interna ou externa, criando, portanto, uma expectativa de controle interna ou externa. Para que a pessoa adquira um locus de controle (expectativa de controle interno ou externo), necessita, primeiramente, atribuir relações causais aos eventos passados.

Weiner (1985) distingue a dimensão de locus de controle da que denomina de locus de causalidade. Para o autor, o locus de causalidade afeta basicamente as emoções, a autoestima, enquanto a expectativa é afetada por uma terceira dimensão, a estabilidade. A noção sobre se a causa de um evento é instável ou estável, conceito de mudança, é o principal determinante da expectativa. Por exemplo, se atribuirmos um mau resultado de um exame à falta de esforço (instável), percebemos que, se nos esforçarmos mais, poderemos ser bem-sucedidos no próximo exame, o que influencia as expectativas de desempenho futuro (Weiner, 1985).

\section{WEINER E A ATRIBUIÇÃO EM CONTEXTOS DE REALIZAÇÃO}

Os trabalhos de Weiner centraram-se, inicialmente, no processo de atribuição relativo ao sucesso e ao insucesso acadêmico na sala de aula, passando, posteriormente, a estudar as relações entre atribuições e emoções, a espontaneidade do processo atribucional no quotidiano e as consequências do pensamento atribucional sobre o comportamento social (Biddle, Hanrahan e Sellars, 2001).

Os pressupostos elaborados por Weiner et al. (1971) asseguram que o empenho das pessoas na realização de uma tarefa depende, em parte, das expectativas de sucesso ou fracasso nessa tarefa específica e acrescentam que essas expectativas 
são determinadas, em grande parte, pelas atribuições causais que estabelecem para os eventos que se seguiram ao seu comportamento ou ao comportamento que observaram em outros. Portanto, as atribuições causais influenciam as expectativas e, por conseguinte, os processos motivacionais (Weiner et al., 1971).

Weiner (1986) admite que a busca de uma explicação para um acontecimento é mais crível ocorrendo fracasso do que sucesso e que, também, é mais provável após um evento inesperado do que depois de um evento esperado. Afirma, ainda, que a importância subjetiva associada ao evento também influencia na busca do conhecimento causal. Lembra que, durante o desempenho de tarefas, estudantes orientados para o fracasso ou desamparados são os que mais tendem a fazer atribuições.

Seguindo de perto a proposta teórica de Heider, Weiner postula que, em contextos relacionados com realização, as pessoas atribuem o resultado, sucesso ou fracasso a determinadas crenças causais. Inicialmente, considerou como principais causas percebidas em contextos de realização quatro elementos atribucionais fundamentais: a capacidade, o esforço, a dificuldade da tarefa e a sorte (Weiner et al., 1971). Esses elementos seriam utilizados pelos indivíduos tanto para interpretar como para predizer resultados e foram enquadrados, num primeiro momento, numa taxonomia atribucional de duas dimensões:

- a primeira dimensão, locus de controle, refere-se ao fato de a causa ser interna ou externa ao indivíduo. Assim, as atribuições relacionadas com a capacidade e o esforço eram classificadas como internas ao indivíduo, enquanto aquelas que diziam respeito à dificuldade da tarefa e à sorte eram classificadas como externas. A origem dessa dimensão encontra-se nas ideias de Heider (1958), que garante que o resultado de uma ação é consequência de uma interação entre duas forças distintas, as relacionadas com a pessoa e as relacionadas com o ambiente;

- a segunda dimensão, estabilidade, é pertinente à forma como a causa varia ao longo do tempo. As atribuições associadas com a capacidade e a dificuldade da tarefa eram classificadas como estáveis, enquanto atribuições relacionadas com o esforço e a sorte eram consideradas como instáveis. Essa dimensão vem, igualmente, na sequência das ideias de Heider (1958), ao dizer que algumas causas, independentemente de poderem evidenciar semelhanças em função do seu nível de internalidade, diferem no que concerne à sua constância ao longo do tempo (Weiner et al., 1971).

Em 1979, Weiner acrescentou uma terceira dimensão ao seu modelo, a controlabilidade, distinguindo os fatores que eram percebidos como sobre o controle do sujeito (por exemplo, esforço) dos que não estão sobre esse controle (capacidade). Essa reformulação tentava clarificar o mal-entendido gerado, entretanto, entre as dimensões locus de controle (conceito de Rotter) e controlabilidade. Assim, Weiner (1979) alterou a designação da dimensão locus de causalidade e acrescentou a dimensão controlabilidade, passando o seu modelo a ser tridimensional.

$\mathrm{Na}$ dimensão locus de causalidade, as causas são partilhadas por fatores internos ou fatores externos ao indivíduo (Weiner, 1979). Para Weiner (1985), nessa 
dimensão estariam incluídas causas como o esforço típico, o esforço imediato, a capacidade, o humor, a fadiga e a doença como fatores internos; e o enviesamento do professor, a dificuldade da tarefa, a sorte e a ajuda não usual de outros como fatores externos.

Na dimensão estabilidade, Weiner (1979) descreve as causas como estáveis (invariantes) ou instáveis (variantes). Assim, a capacidade, o esforço típico, o enviesamento do professor, a família e a dificuldade da tarefa podem ser vistos como relativamente estáveis; o esforço imediato, o humor, a fadiga, doenças, a ajuda não usual de outros, a sorte podem ser vistos como mais instáveis.

Para Weiner (1986), essa dimensão tem especial influência nas alterações das expectativas de desempenho futuro. Atribuições causais após sucesso, associadas a fatores estáveis, produzem aumento nas expectativas de sucesso futuro e geram diminuição nas expectativas após o(s) fracasso(s). Quanto ao aspecto afetivo, a atribuição de causas estáveis para o fracasso, como a capacidade e a dificuldade da tarefa (que dificilmente variarão), tendem a suscitar emoções de falta de confiança e de desânimo. A atribuição a causas estáveis como a capacidade e o esforço típico para o sucesso tendem a suscitar sentimentos de segurança e confiança (Barros, J. H. e Barros, A. M., 1990).

A dimensão controlabilidade consiste em perceber se a causa atribuída é controlável ou não pelo sujeito. Causas como a capacidade, a dificuldade da tarefa, a sorte, o enviesamento do professor e a ajuda dos outros seriam vistos como incontroláveis pelo sujeito, porém a ajuda dos outros e o enviesamento dos outros e o enviesamento do professor são controláveis, só que não pelo aluno. A dificuldade da tarefa, a sorte, a capacidade, o humor, a fadiga e a doença são vistos como incontroláveis. A dimensão de controlabilidade está associada a emoções, como a gratidão em caso de sucesso atribuído à ajuda de outros e à raiva em caso de fracasso em função de interferência externa. Essa dimensão está, igualmente, associada a emoções de vergonha e culpa em caso de fracasso atribuído a fatores internos, mas o indivíduo vivencia a emoção de orgulho se atribuir o seu sucesso a causas controláveis por si próprio, por exemplo, ao seu esforço (Weiner, 1986).

A atribuição para causas de fracasso ou sucesso a fatores internos ou externos propicia fortes reações emocionais com repercussões ao nível da autoestima. Assim, atribuições de capacidade e esforço para o sucesso facilitam o aparecimento de sentimentos de orgulho, competência e satisfação. Atribuições de capacidade e esforço para o fracasso propiciam sentimentos de incompetência e vergonha. Para Weiner, a autoestima e a expectativa de desempenho futuro interferem no desempenho de realização de tarefas (apud Barros, J. H. e Barros, A. M., 1990).

Weiner (1986) afirma que as pessoas tenderiam a explicar os seus desempenhos, à falta ou à presença de capacidade, à falta de esforço ou a um esforço adequado, à dificuldade da tarefa e à má ou boa sorte (ou destino). Em vários trabalhos, Weiner $(1979,1985,1986)$ diz que fatores como o humor, a fadiga, a doença ou o viés poderiam servir como causas necessárias e/ou suficientes para o desempenho. Posteriormente, indica como causas mais relevantes ao desempenho a capacidade, o esforço, a facilidade ou dificuldade da tarefa, a sorte, o humor e o auxílio ou os obstáculos criados por outros (Graham e Weiner, 1996). 
Em 1985, Weiner expandiu o seu modelo tridimensional de atribuições para uma teoria atribucional da motivação e emoção em contextos de desempenho. $\mathrm{O}$ autor entende que as pessoas, em geral, para além de se sentirem alegres (quando o acontecimento é percepcionado como positivo) ou tristes (quando o acontecimento é percepcionado como negativo), no seu dia a dia, procuram as causas que estão por detrás desses resultados. Essa busca é mais provável quando se trata de um resultado negativo, inesperado ou importante. Um resultado poderá, assim, gerar emoção positiva (dependente do resultado e independente da atribuição) particularmente se esse resultado estiver de acordo com as expectativas. A estabilidade percebida será, então, um fator que influencia as expectativas de sucesso futuro, reconhecendo-se que as atribuições poderão ser afetadas por vários antecedentes. Por outro lado, quando o resultado é negativo, inesperado e/ou importante, tenta identificar-se a causa que o originou, a qual determinará o tipo e a emoção que se vai sentir. Assim, um aluno que vê o seu resultado positivo como consequência da sorte se sentirá surpreendido, sendo essa emoção dependente da atribuição, e não do resultado (Fonseca, 1999).

Weiner (1985) enuncia, igualmente, o princípio da expectativa, no qual afirma que a estabilidade percebida das causas influencia as expectativas individuais de sucesso no futuro, as quais, por sua vez, influenciam futuros desempenhos. Assim, se o resultado de um acontecimento é atribuído a uma causa estável, então existirá uma expectativa mais elevada de esse resultado voltar a ocorrer. Por outro lado, se o resultado de um acontecimento é atribuído a uma causa instável, então se criará a expectativa de esse resultado poder ser alterado, ou de o futuro poder ser antecipado de forma diferente do passado. Logo, resultados atribuídos a causas estáveis serão antecipados como tendo maior grau de certeza de ocorrência no futuro do que os resultados atribuídos a causas instáveis (Weiner, 1985). Uma consequência importante desse princípio é a de que as atribuições influenciam as expectativas dos alunos para sucessos futuros, as quais, por sua vez, podem determinar se uma pessoa opta ou não por continuar a participar/investir em determinada atividade (Fonseca, 1999).

Da mesma forma, determinadas emoções, como as relacionadas com a autoestima, não dependem da causa percebida, mas, sim, das suas propriedades dimensionais. Estudos realizados por Russell e McAuley (1986) vêm apoiar a importância das dimensões causais na relação entre atribuição e emoção. Segundo Biddle (1993), pode-se considerar que, a uma crescente complexidade cognitiva, corresponde mais diferenciação das emoções experienciadas. Além disso, a percepção dos indivíduos sobre as causas atribuídas a um resultado pode influenciar não só as expectativas futuras relativamente a acontecimentos similares, mas também as emoções após a obtenção desse resultado. Como consequência, ao influenciarem as emoções, as atribuições influenciam também os comportamentos em situação de desempenho.

Quando um resultado positivo é atribuído internamente, um aluno sente orgulho e autoestima positiva, mantendo-se envolvido nas atividades. Quando um resultado negativo é atribuído internamente, um aluno, habitualmente, sente menor autoestima, o que, por sua vez, pode conduzir à diminuição do envolvimento voluntário na atividade (Barros, 1992). No entanto, segundo Weiner (1992), não é 
apenas a dimensão da causalidade que influencia as emoções. O desânimo, a culpa e a vergonha estarão também relacionados com as atribuições. Se um resultado negativo é atribuído a causas estáveis, frequentemente o resultado é o desânimo. Emoções relacionadas com o desânimo e a vergonha tendem na diminuição da participação e desistência, sendo a vergonha sentida quando um resultado negativo é atribuído a causas internas e incontroláveis. A culpa decorre de um resultado atribuído a causas internas e controláveis. Emoções relacionadas com a vergonha resultam, muitas vezes, numa motivação acrescida e em novos processos de reatribuição. Em suma, as atribuições influenciam futuros comportamentos, como os associados com a motivação e a participação nas atividades em contextos de realização (Weiner, 1992).

\section{DIMENSÕES E PROCEDIMENTOS DE AVALIAÇÃO ATRIBUCIONAL: O CONTRIBUTO DE RUSSELL}

Tem existido alguma discussão sobre a natureza e o número de dimensões atribucionais. Embora a maioria dos autores siga o modelo proposto por Weiner (1979), existem vários estudos (Elig e Frieze, 1979; Hanrahan, Grove e Hattie, 1989) que têm apontado para a existência e relevância de outras dimensões. Entre estas, destacam-se, com mais suporte, a da intencionalidade e a da globalidade.

A dimensão da intencionalidade, proposta por Elig e Frieze (1979), refere-se ao grau de intenção voluntária que existe em determinado comportamento. A sua origem vem desde os estudos iniciais de Heider (1958), no entanto a investigação atual não é unânime na aceitação da sua validade enquanto dimensão autônoma. Kelley e Michela (1980) salientaram a confusão existente entre as dimensões intencionalidade e locus de causalidade, enquanto Russell (1982) alertou para a sua semelhança com a dimensão da controlabilidade. O próprio Weiner (1986) defendeu que a intencionalidade e a controlabilidade devem ser incluídas numa mesma dimensão, sob a designação de controlabilidade.

A dimensão da globalidade baseia-se nos estudos sobre desânimo aprendido de Abramson, Seligman e Teasdale (1978). Essa dimensão, originalmente utilizada na investigação, em relação com a depressão, refere-se à percepção dos indivíduos sobre a generalização do impacto das causas do resultado de determinado acontecimento nos resultados de outros acontecimentos distintos. Apesar de algumas críticas apresentadas por Weiner $(1979,1986)$ à falta de clareza dessa dimensão, a aceitação da dimensão da globalidade, enquanto dimensão ligada ao estilo atribucional, tem sido comum. Por exemplo, McAuley, Duncan e Russell (1992) afirmam que a dimensão globalidade se relaciona com o modo como as pessoas geralmente percebem os resultados, o que a aproxima mais das abordagens dos estilos atribucionais dos indivíduos e a afasta da análise das atribuições relativas a acontecimentos particulares.

Segundo Biddle e Hanrahan (1998), o maior problema na definição do número de dimensões atribucionais encontra-se no fato de muita da pesquisa realizada se basear na categorização dimensional determinada à partida pelos investigadores, em vez de os indivíduos estudados relatarem de forma livre e espontânea a sua categorização atribucional. McAuley e Duncan (1990) apontaram a necessidade 
de tornar mais válida essa categorização, assumindo que a compreensão dos comportamentos evidenciados pelos sujeitos avaliados depende em muito da fiabilidade dos procedimentos de investigação. Fonseca (1999) levanta uma questão similar: existirão as três dimensões weinerianas, ou serão elas em maior ou menor número? De fato, não parece haver consenso relativo ao número de dimensões atribucionais. A eventual inconsistência na investigação pode decorrer das diferentes metodologias empregues nos estudos (Fonseca, 1999).

McAuley, Duncan e Russell (1992) alertaram para o erro vulgarmente existente nas metodologias de avaliação das atribuições causais. Grande parte da investigação inicial sobre as atribuições consistia em pedir aos sujeitos para indicar a importância que, na sua opinião, cada um dos quatro elementos causais, inicialmente propostos por Weiner et al. (1971), havia assumido no resultado obtido. Posteriormente, os investigadores dos processos atribucionais utilizaram uma abordagem baseada em checklists para avaliar as atribuições individuais (Vallerand, 1987). Estas eram analisadas pelo próprio investigador, que, ao recolher as atribuições causais elaboradas pelos respondentes, as classificava nas dimensões de acordo com os princípios veiculados na teoria de Weiner. Russell (1982) destacou os problemas que podem surgir, quando os investigadores tentam classificar as atribuições realizadas pelos indivíduos ao longo das dimensões atribucionais, concluindo da análise efetuada que investigadores e homens comuns classificam de modo diferenciado as causas dos acontecimentos.

Russell (1982) afirma que, se um indivíduo atribui a causa de um mau desempenho aos adversários terem jogado melhor, não se pode determinar se o indivíduo se refere a uma causa externa ou interna. De fato, a partir do momento que o processo de atribuição de causalidade depende da percepção individualizada de determinado resultado, torna-se necessário que seja o próprio indivíduo a caracterizar as causas ao longo das diferentes dimensões. Fonseca (1999) exemplifica essa situação aludindo a um atleta que, ao ser questionado, justificou o pior resultado da sua carreira desportiva com a sua má condição física. De acordo com o método de avaliação das atribuições anteriormente indicado, a causa deveria ser classificada como interna, instável e controlável, no entanto o atleta considerava que a sua má forma física refletia, fundamentalmente, uma planificação deficiente do seu processo de treino por parte do treinador. Nessa medida, a classificação da causa indicada foi, naturalmente, diferente da que seria realizada com base no modelo tradicional de avaliação causal. Assim, ao classificar as causas apresentadas pelos atletas, o investigador incorreria assim no que Russell (1982) denominou de "erro fundamental do investigador de atribuição", já que a classificação da causa dependia sempre do significado subjetivo dado pelo investigador.

$\mathrm{Na}$ tentativa de resolver algumas das questões da avaliação dos processos atribucionais, Russell (1982) desenvolveu a causal dimensional scale (CDS), baseando-se no modelo tridimensional de Weiner (1979) (locus de causalidade, estabilidade e controlabilidade), permitindo aos respondentes a classificação das suas próprias atribuições ao longo das dimensões causais. Esse procedimento, segundo Russell (1982), tenderia a reduzir os problemas decorrentes da interpretação das atribuições feitas pelos investigadores, visto que seria o sujeito, e não 
o experimentador, a decidir sobre as propriedades dimensionais dos elementos atribucionais. Assim, ao preencher a CDS, o indivíduo começa por indicar a causa (ou causas) que considera ter estado na base do seu resultado; em seguida, analisando cada causa individualmente, responde a nove questões, numa escala Likert de 9 pontos, de forma a possibilitar a classificação da causa indicada em função do modelo tridimensional de Weiner.

\section{ATRIBUIÇÕES CAUSAIS DO DESEMPENHO ESCOLAR E SUAS IMPLICAÇÕES}

Os processos atribucionais têm sido amplamente aplicados ao contexto escolar. Bar-Tal (1982) sugere que a avaliação da realização escolar dos alunos envolve percepções causais de professores e alunos relativamente ao sucesso e ao fracasso. Essas percepções determinam, por sua vez, o comportamento dos professores diante dos alunos, os quais contribuem para influenciar as atribuições causais dos alunos e o seu desempenho acadêmico.

Uma das primeiras preocupações dos estudos das atribuições causais consistiu em identificar as principais causas utilizadas por alunos e professores para explicar o sucesso e o insucesso escolar. Inicialmente, grande parte das investigações realizadas procurou avaliar a importância de apenas quatro causas para a realização: capacidade, esforço, dificuldade da tarefa e sorte (Barros, 1992). Atualmente, entende-se que essa investigação, baseada num trabalho de Weiner e colaboradores, não captava toda a complexidade subjacente aos processos atribucionais. Essas quatro causas não são as únicas explicações percebidas para o sucesso e insucesso escolar (Barros, 1992).

Barros, A. M. e Barros, J. H. (1990) afirmam que algumas dessas causas podem até não fazer parte do reportório cognitivo do sujeito em determinadas situações, dando, igualmente, conta da multiplicidade de causas que podem ser fornecidas pelos alunos para explicar o seu desempenho acadêmico. Os autores evidenciam uma assimetria entre algumas causas fornecidas para explicar o sucesso e o insucesso, deixando, igualmente, antever a hipótese da existência de um padrão atribucional egodefensivo, amplamente referido em diferentes investigações, segundo as quais os sujeitos tendem a assumir a responsabilidade pelos seus sucessos e a rejeitar a responsabilidade pelos seus insucessos (Barros, A. M. e Barros, J. H., 1990).

No estudo realizado por Barros, A. M. e Barros, J. H. (1990), a compreensão da matéria foi vista pelos alunos como a causa mais importante para o sucesso, enquanto o ambiente na família e a ansiedade do aluno foram considerados como as causas mais importantes para explicar o insucesso. Barros e Almeida (1991) encontraram algumas diferenças etárias quanto às diversas explicações causais utilizadas pelos alunos. Por exemplo, o método de ensino do professor foi considerado mais importante pelos alunos mais novos, enquanto a competência do professor foi vista como mais importante pelos alunos mais velhos. É possível que as mudanças nas atribuições estejam relacionadas com as experiências educativas dos alunos e que elas resultem da modelação exercida pelas atribuições dos pais e dos professores. 
Para Weiner (1986), autoestima, autoconceito e expectativas são fatores determinantes do desempenho e são influenciados pelas atribuições causais. A descoberta de que a motivação e o comportamento estão relacionados com a atribuição de causalidade tem importantes implicações nas estratégias de intervenção pedagógica, na medida em que alterando-se o tipo de atribuição se poderá influenciar diretamente a motivação para a realização e, consequentemente, o desempenho futuro (Piccinini, 1988).

Weiner (1986) acredita que a teoria da atribuição causal integra o pensamento, o sentimento e a ação. Sempre que um evento positivo ou negativo ocorre, existe determinado estado emocional. Se o resultado do evento é positivo, sentimos prazer, felicidade e bem-estar; se é negativo, sentimos tristeza, insatisfação e culpa. Essas emoções dependem das características do evento, do resultado atingido e antecedem as atribuições, sendo independentes destas.

Rodrigues (1984), num estudo realizado no Brasil para averiguar a relação entre a capacidade das atribuições para sucesso e fracasso em situações de realização escolar e a mediação de emoções e expectativas de comportamento futuro, encontrou resultados semelhantes.

Weiner, Russell e Lerman (1978) descrevem o estudo em que verificaram que, quando o sucesso é atribuído à capacidade, os sujeitos vivenciam emoções como felicidade, competência, confiança e orgulho; quando o sucesso é atribuído ao esforço, vivenciam sentimentos de felicidade, orgulho, competência e satisfação; quando o sucesso é atribuído à sorte, vivenciam surpresa e culpa; quando o sucesso é atribuído à ajuda de outros, suscita gratidão; quando ocorre fracasso, e este se atribui à falta de capacidade, os indivíduos descrevem sentimentos de incompetência; se à falta de esforço, culpa e vergonha; se à sorte, surpresa; se à interferência de outros, hostilidade.

O estudo de Rodrigues (1984) confirmou algumas relações entre emoções e categorias atribucionais, como competência, confiança e orgulho perante a atribuição de sucesso à capacidade; e felicidade, orgulho, competência e satisfação quando o sucesso era atribuído ao esforço, embora com níveis percentuais diferentes do estudo de Weiner, Russell e Lerman (1978), porém não reconheceu algumas relações como: culpa perante atribuição de sucesso à sorte e incompetência na atribuição de fracasso à capacidade. Contudo, temos de considerar que o seu estudo diferiu nas categorias causais averiguadas e nas emoções passíveis de indicação pelos sujeitos. Parece ficar claramente estabelecido o papel mediador das atribuições causais na vivência de emoções em situações de realização. Para Weiner, Russell e Lerman (1978), essas emoções influenciam a autoestima e o autoconceito do indivíduo, com repercussões ao nível da realização escolar.

Rodrigues (1984) cita alguns estudos em que os investigadores relacionam a atribuição de causalidade a eventos frustradores. Outros investigam as atribuições de causalidade segundo o modelo de atores e observadores. A atribuição de causas a acontecimentos vitimadores representa outra vertente de estudos, bem como trabalhos enfatizando o locus de controle (Rotter, 1966). O último tipo de estudos citado por Rodrigues versa a atribuição de causalidade a eventos de sucesso e fra- 
casso. As pesquisas sobre atribuição de causalidade a situações de sucesso e fracasso baseiam-se principalmente no modelo atribucional de Weiner et al. (1971).

As atribuições feitas às causas de sucesso e fracasso em contexto de realização escolar provocam reações emocionais e provocam alterações na autoestima, no autoconceito e nas expectativas de desempenho do aluno. As atribuições também influenciam as expectativas dos professores e ajudam a determinar as suas ações futuras em relação aos alunos. A estabilidade influencia as expectativas de sucesso futuro, e o locus de causalidade e a controlabilidade suscitam reações afetivas, que agem sobre a autoestima e o autoconceito (Barros, A. M. e Barros, J. H., 1990).

Coll (2000) afirma que os padrões de atribuição que mais favorecem a aprendizagem são aqueles em que a pessoa atribui a causas internas, instáveis e controláveis tanto o sucesso como o fracasso. A atribuição de sucessos a causas externas, instáveis e incontroláveis - como a sorte -, em termos de padrões de atribuição, é a mais desfavorável, por produzir impressão de falta de controle, tanto para produzir o sucesso como para evitar o fracasso (Reid, 2007).

Conforme as atribuições que os alunos façam para os seus sucessos e fracassos, assim serão as repercussões na autoestima, no autoconceito e nas expectativas futuras. Esse fato traduz-se em maior ou menor persistência nas atividades, no evitar ou na procura de tarefas consideradas mais difíceis e numa influência relevante em todos os processos motivacionais para a realização (Barros, 1992; Bénabou e Tirole, 2003). Weiner (1986) afirma que, nesses casos, se torna necessário um programa de treino de mudanças de expectativas ou de autoconceito de causas percebidas de desempenho. Provavelmente, visto que o esforço pode ser aumentado pela vontade, atribuições de não consecução de um objetivo à falta de esforço resultarão na manutenção da esperança e aumentarão a persistência em direção ao objetivo. Por outro lado, dado que a capacidade é estável e não sujeita a controle volitivo, atribuição de não consecução de um objetivo à baixa capacidade resulta em desistência e cessação do comportamento orientado para o objetivo (Weiner, 1986).

A teoria da atribuição iniciada por Heider indica que os comportamentos dos alunos são influenciados por expectativas, determinando, em muitos casos, o sucesso ou o insucesso escolar. Por exemplo, perante uma disciplina, se o aluno considerar que a sua aprovação dependerá apenas do seu esforço, a sua forma de agir será consideravelmente diferente do que se pensar que o professor fará tudo para o reprovar. Nesse último caso, o indivíduo não visualizará uma relação controlável por ele, determinando fortemente as suas ações futuras, esforço, empenho e motivação (Fiske e Taylor, 1984).

Mussen et al. (1998) afirmam que reeducar a interpretação das causas não só leva a mudanças na compreensão, mas ao aperfeiçoamento das expectativas de sucesso, percepção da autoeficácia, persistência e desempenho da tarefa, contudo não se pode ensinar ao aluno que os seus fracassos são apenas fruto de falta de esforço se houver outras causas presentes, como, por exemplo, um mau professor, fracos recursos materiais ou métodos de ensino inadequados. Mussen et al. (1998) questionam, também, outro aspecto a ser observado nesse tipo de intervenção, acrescentando que ensinar às crianças que os seus fracassos são em razão da falta de esforço pode ser prejudicial se elas não tiverem as capacidades apropriadas para a tarefa. 
O papel de ajudar os alunos a fazerem atribuições internas mais favoráveis à aprendizagem cabe em grande parte aos professores, mas estes, em muitos casos, necessitam ter os seus próprios padrões de atribuição ajustados, a fim de criarem expectativas mais adequadas em relação ao desempenho futuro dos seus alunos (Covington e Omelich, 1979). Weiner e Kukla (1970) acreditam que as falsas expectativas do professor o levam a ter comportamentos/atitudes que influenciam o desempenho futuro do aluno. Weiner (1985) afiança que, quando avaliamos os comportamentos dos outros, damos mais importância ao esforço do que à capacidade. Por exemplo, em caso de sucesso, recompensa-se mais o indivíduo cujo sucesso seja atribuído ao esforço do que se for atribuído à capacidade. Segundo o mesmo autor, no que diz respeito ao insucesso, pune-se mais se for atribuído à falta de esforço do que à falta de capacidade.

Weiner (1985) afirma que determinadas atribuições (de estabilidade ou instabilidade) afetam as expectativas, influenciando o desempenho em determinada atividade, acrescentando que as expectativas também influenciam no momento de atribuirmos causas ao fracasso e ao sucesso, constituindo-se como um processo dinâmico e em constante interação. As expectativas dependem da percepção de capacidade versus a dificuldade percebida da tarefa, mais a estimativa do esforço pretendido e da sorte antecipada. Dessa forma, as expectativas são fortemente determinadas pelas experiências anteriores.

Muitos fatores interferem nas expectativas dos professores, e essas expectativas direcionam em parte as atribuições que ocorrerão sobre o desempenho dos alunos. Atribuições inadequadas não só influenciarão as expectativas futuras, mas também o comportamento desses professores no tocante aos alunos, como recompensas, punições e estímulos (Covington e Omelich, 1979; Brophy, 2010).

Outros estudos vêm demonstrando que os professores estão a fazer novas atribuições sobre o fracasso escolar, deslocando-o, do âmbito da escola e do professor, para o aluno e para a família (Gama e Jesus, 1994; Maluf e Bardelli, 1991; Oliveira, 1998). Padrões de atribuição de fracasso centrados no aluno determinam, por vezes, esquemas de recompensas e punições inócuos ou prejudiciais e a não implementação de ações efetivas de combate ao insucesso por parte do professor (Barros, Barros e Monteiro Neto, 1993).

Os dados da teoria da atribuição e o conhecimento dos padrões atribucionais que caracterizam os professores e os alunos se revestem de grande importância para a compreensão dos comportamentos de realização escolar. Como asseguram Kelley e Michela (1980), as atribuições condicionam as nossas reações afetivas acerca dos acontecimentos passados, as nossas expectativas acerca dos acontecimentos futuros, as nossas atitudes e reações perante o comportamento das outras pessoas, as nossas concepções acerca de nós próprios e os nossos esforços para melhorar o nosso futuro.

As atribuições constituem determinantes importantes das expectativas e dos comportamentos dos indivíduos. Desse modo, é de prever que, se os professores acreditarem que o sucesso ou o insucesso dos seus alunos é causado por fatores estáveis, esperarão que o mesmo resultado seja repetido no futuro; se o insucesso for atribuído a fatores instáveis e controláveis, os professores serão levados a crer que os alunos obterão sucesso no futuro. Contudo, se o sucesso ou o insucesso for atribuído 
a causas instáveis e incontroláveis, os professores não poderão prever o resultado futuro dos seus alunos. Concomitantemente, as expectativas dos professores quanto ao desempenho futuro dos seus alunos não só influenciam o seu comportamento e a sua atitude na sala de aula, mas também interferem nas atribuições causais dos seus alunos (Barros e Almeida, 1991).

O professor deve associar os sucessos e os insucessos dos seus alunos a fatores que possa controlar, contribuindo, assim, para o desenvolvimento de experiências educativas mais motivadoras. Esse esforço passa, provavelmente, por uma organização do processo ensino-aprendizagem diferente da tradicional. O papel do professor não se esgota na transmissão de conhecimentos, nem o papel do aluno consiste na mera recepção desses mesmos conhecimentos. Um conhecimento individual do aluno deve ser reclamado como forma de, minimamente, se conseguir interligar ensino e aprendizagem, e de ligar aprendizagem ao desenvolvimento sociocognitivo e este à construção de conhecimento.

Adotando crenças causais para o mau desempenho dos alunos, como a falta de esforço e falta de capacidade do aluno, desinteresse e condições socioeconômicas da família, torna-se difícil esperar que esses professores avaliem adequadamente a influência dos seus próprios comportamentos no desempenho do aluno. Dessa forma, não é fácil verificar uma mudança comportamental do professor no sentido de melhorar a sua competência de ensino, apresentando novos métodos e técnicas de ensino, tornando o ensino mais eficaz. A análise que esses professores farão do sistema educacional e da escola dificilmente contribuirá para a alteração de padrões e de estruturas inadequadas de ensino-aprendizagem. Conclui-se que as atribuições que os alunos e os professores fazem sobre o sucesso ou fracasso escolar interferem significativamente no desempenho dos alunos, conduzindo a um aumento na motivação e no sucesso ou ao abandono e fracasso escolar.

Os dados da teoria da atribuição e o conhecimento dos padrões atribucionais que caracterizam os professores e os alunos revestem-se de grande importância ao nível da realização escolar. As atribuições causais do sucesso e do insucesso influenciam os comportamentos de aprendizagem e de realização escolar, como a persistência, o interesse e a intensidade colocados na execução das tarefas.

\section{CONSIDERAÇÕES FINAIS}

De forma geral, podemos afirmar que a teoria da atribuição causal estuda as regras, os processos e os mecanismos que as pessoas utilizam no seu esforço de compreensão dos acontecimentos e dos seus comportamentos quotidianos, atribuindo causalidade aos fatos, tendo por objetivo tornar inteligível a realidade que percepcionam e vivenciam. Nesse processo de compreensão da realidade, a teoria cognitiva destaca o fato de as pessoas serem cientistas, embora intuitivas, fazendo um processamento objetivo da informação que recebem como resposta a uma necessidade individual de natureza cognitiva — a da compreensão e interpretação do meio em que vivem (Dweck, 1986).

Numa perspetiva motivacional, o que os mecanismos de atribuição causal de um indivíduo tornam relevantes são uma resposta às necessidades individuais de 
natureza psicossocial, tais como a manutenção da autoestima, a percepção da competência e a aprovação social. Os processos atribucionais constituem uma variável importante, quer nos alunos, quer nos professores. As atribuições causais que os alunos e os professores processam a respeito do sucesso ou do insucesso acadêmico consistem em fatores determinantes das suas expectativas relativas às suas capacidades e ao seu desempenho. É por isso que se considera a teoria atribucional como uma teoria motivacional (Weiner, 1985).

Conhecer e compreender as atribuições de causalidade dos alunos podem oferecer importantes subsídios para a planificação das atividades de ensino-aprendizagem e para a implementação de comportamentos que favoreçam o desenvolvimento de crenças compatíveis com a motivação para a aprendizagem e com o bom desempenho escolar (Boruchovitch e Martini, 1997; Brophy, 2010). As modificações no padrão atribucional dos alunos devem ocorrer num trabalho conjunto com os professores e com toda a escola, em busca da construção de um ambiente de cooperação, interações positivas, esforço e reconhecimento das capacidades e aptidões do aluno, com vista à superação das suas dificuldades acadêmicas.

\section{REFERÊNCIAS}

ABRAMSON, L. Y.; SELIGMAN, M. P.; TEASDALE, J. D. Learned helplessness in human: Critique and reformulation. Journal of Abnormal Psychology, v. 87, n. 1, p. 49-74, 1978. https://psycnet.apa.org/doi/10.1037/0021-843X.87.1.49

BARROS, A. M.; ALMEIDA, L. S. Dimensões sociocognitivas do desempenho escolar. In: ALMEIDA, L. S. (org.). Cognição e Aprendizagem Escolar. Porto: Associação dos Psicólogos Portugueses, 1991. p. 87-97.

BARROS, A. M.; BARROS, J. H. Atribuições causais do sucesso e insucesso escolar em alunos do $3^{\circ}$ ciclo do ensino básico e do ensino secundário. Revista Portuguesa de Psicologia, n. 26, p. 119-138, 1990.

BARROS, J. H. Professores e alunos pigmaliões. Coimbra: Livraria Almedina, 1992. BARROS, J. H.; BARROS, A. M. Variáveis sociocognitivas do professor: teoria e investigação. Revista Portuguesa de Psicologia, n. 26, p. 95-117, 1990.

BARROS,J.H.; BARROS, A. M.; MONTEIRO NETO, F. F. Psicologia do controlo pessoal: aplicações educacionais, clínicas e sociais. Braga: Universidade do Minho, 1993. BAR-TAL, D. The effects of teacher's behaviour on pupil's attributions: a review. In: ANTAKI, C.; BREWIN, C. R. (orgs.). Attributions and psychological change: applications of attributional theories to clinical and educational practice. Nova York: Academic Press, 1982. p. 177-194.

BÉNABOU, R.; TIROLE, J. Intrinsic and extrinsic motivation. Review of Economic Studies, v. 70, n. 3, p. 489-520, 2003. https://doi.org/10.1111/1467-937X.00253

BIDDLE, S. J. Attributional research and sport psychology. In: SINGER, R. N.; MURPHEY, M.; TENNANT, L. K. (orgs.). Handbook of research on sport psychology. Nova York: MacMillan, 1993. p. 437-464. 
BIDDLE, S. J.; HANRAHAN, S. Attributions and attributional style. In: DUDA, J. L. (org.). Advances in sport and exercise psychology measurement. Morgantown: Fitness information Technology, 1998. p. 3-199.

BIDDLE, S. J.; HANRAHAN, S.; SELLARS, C. Attributions: Past, present and future. In: SINGER, R.; HAUSENBLAS, H.; JANELLE, C. (orgs.). Handbook of sport psychology. 2. ed. Nova York: John Wiley \& Sons, 2001. p. 444-471.

BORUCHOVITCH, E.; MARTINI, M. As atribuições de causalidade para o sucesso e fracasso escolar e a motivação para a aprendizagem de crianças brasileiras. Arquivos Brasileiros de Psicologia, v. 49, p. 59-70, 1997.

BROPHY, J. Motivating students to learn. 3. ed. Nova York: Routledge, 2010. COLL, C. Psicologia do ensino. Porto Alegre: Artmed, 2000.

COVINGTON, M.; OMELICH, C. Are causal attributions causal? A path analysis of the cognitive model of achievement motivation. Journal of Personality and Social Psychology, v.37, n. 9, p. 1487-1504,1979. https://psycnet.apa.org/doi/10.1037/00223514.37.9.1487

CUNNINGHAM,J.D.; STARR, P.A.; KANOUSE, D. E. Self as actor, active observer, and passive observer: Implications for causal attributions. Journal of Personality and Social Psychology, v. 37, n. 7, p. 1146-1152, 1979. http://dx.doi.org/10.1037/00223514.37.7.1146

DWECK, C. S. Motivational processes affecting learning. American Psychologist, v. 41, n. 10, p. 1040-1048, 1986. https://psycnet.apa.org/doi/10.1037/0003-066X.41.10.1040 ELIG, T. W.; FRIEZE, I. H. Measuring causal attributions for success and failure. Journal of Personality and Social Psychology, v. 37, n. 4, p. 621-634, 1979.

FISKE, S. T.; TAYLOR, S. E. Social Cognition. Reading: Addison-Wesley, 1984.

FONSECA, A. M. Atribuições em contexto de actividade física ou desportiva: Perspectivas, relações, implicações. 1999. Dissertação (Doutoramento) - Faculdade de Ciências do Desporto e de Educação Física do Porto, Universidade do Porto, Porto, 1999.

GAMA, E. M.P.; JESUS, D. M. Atribuições e expectativa do professor: representações sociais na manutenção da selectividade social na escola. Psicologia:Teoria e Pesquisa, v. 10, n. 3, p. 393-410, 1994.

GAWRONSKI, B. Theory-based bias correction in dispositional inference: The fundamental attribution error is dead, long live the correspondence bias. European Review of Social Psychology, v. 15, n. 1, p. 183-217, 2004. https://doi. org/10.1080/10463280440000026

GRAHAM, S.; WEINER, B. Theories and principles of motivation. In: BERLINER, D. C.; CALFEE, R. C. (orgs.). Handbook of educational psychology. Nova York: Sincom \& Shuster MacMillan, 1996. p. 63-84.

GRAHAM, S.; WILLIAMS, C. An attributional approach to motivation in school. In:WENTZEL, K. R.; WIGFIELD, A. (orgs.). Handbook of Motivation in School. Nova York: Routledge, 2009. p. 35-55. 
HANRAHAN, S.; GROVE, J.; HATTIE, J. Development of a questionnaire measure of sport-related attributional style. International Journal of Sport Psychology, v. 20, n. 2, p. 114-134, 1989.

HEIDER, F. The psychology of interpersonal relations. Nova York: John Wiley \& Sons, 1958.

HEWSTONE, M. Causal attribution: from cognitive processes to collective beliefs. Oxford: Blackwell Publishers, 1989.

HEWSTONE, M.; FINCHAM, F. Attribution theory and research: Back issues and applications. In: HEWSTONE, M.; STROEBE, W.; STEPHENSON, G. M. (orgs.). Introduction to social psychology: a European perspective. 2. ed. Oxford: Blackwell Publishers, 1996. p. 167-204.

JONES, E. E.; DAVIS, K. E. From act to disposition: the attribution process in person perception. In: BERKOWITZ, L. (org.).Advances in Experimental Social Psychology. 2. ed. Nova York: Academic Press, 1965. p. 219-266.

JONES, E. E.; NISBETT, R. E. The actor the observer: divergent perceptions of the causes of behaviour. In: JONES, E. E. (org.). Attribution: perceiving the causes of behaviour. Morritow: General Leaning Process, 1972. p. 79-94.

KELLEY,H.H.Attribution theory in social interaction. In: VINE, D. L. (org.). Nebraska symposium on motivation. Lincoln: University of Nebraska Press, 1967. p. 192-238.

KELLEY, H. H. Attribution in social interaction. Nova York: General Learning Press, 1972.

KELLEY, H. H. The processes of causal attribution. American Psychologist, v. 28, n. 2, p. 107-128, 1973. https://psycnet.apa.org/doi/10.1037/h0034225

KELLEY, H. H.; MICHELA, J. Attribution theory and research. Annual Review of Psychology, v. 31, p. 457-501, 1980. https://doi.org/10.1146/annurev. ps.31.020180.002325

MALLE, B. F. The Actor-Observer Asymmetry in Attribution: A (Surprising) Meta-Analysis. Psychological Bulletin, v. 132, n. 6, p. 895-919, 2006. https://doi. org/10.1037/0033-2909.132.6.895

MALLE, B. F. Attribution Theories: How People Make Sense of Behavior. In: CHADEE, D. (org.). Theories in social psychology. Nova York: Wiley-Blackwell, 2011. p. 72-95.

MALUF, M. R.; BARDELLI, C. As causas do fracasso escolar na perspectiva de professores e alunos de uma escola de primeiro grau. Psicologia: Teoria e Pesquisa, v. 7, n. 3, p. 263-271, 1991.

MARIĆ, M.; SAKAČ, M. Individual and social factors related to students'academic achievement and motivation for learning. Suvremena Psihologija, v. 17, n. 1, p. 63-79, 2014.

MCAULEY, E.; DUNCAN,T. E. The causal attribution process in sport and physical activity. In: GRAHAM, S.; FOLKES, V. S. (orgs.). Attribution theory: applications to achievement, mental health and interpersonal conflict. Hillsdale: L. Erlbaum Associates, 1990. p. 37-52. 
MCAULEY, E.; DUNCAN, T.E.; RUSSELL, D. Measuring causal attributions: The revised causal attributions scale (CDS-II). Personality and Social Psychology Bulletin, v. 18, n. 5, p. 566-573, 1992. http://doi.org/10.1177/0146167292185006

MONROE, A. E.; MALLE, B. F. From uncaused will to conscious choice: The need to study, not speculate about, people's folk concept of free will. European Review of Philosophy, v. 1, p. 211-224, 2010. https://doi.org/10.1007/s13164-009-0010-7

MUSSEN, P. H.; CONGER, J. J.; KAGAN, J.; HOUSTON, A. C. Desenvolvimento e personalidade da criança. 2. ed. São Paulo: Harbra, 1998.

OLIVEIRA, L. B. Atribuição de causalidade à repetência escolar na percepção de professores, pais e alunos. 1998. Tese (Mestrado em Educação) - Faculdade de Filosofia e Ciências, Universidade Estadual Paulista “Júlio de Mesquita Filho”, Marília, 1998.

PALOS, R.; MUNTEANU, A.; COSTEA, I.; MACSINGA, I. Motivational and cognitive variables with impact on academic performance - Preliminary study. Procedia Social and Behavioral Sciences, v. 15, p. 138-142, 2011. https://doi.org/10.1016/j. sbspro.2011.03.063

PICCININI, C. O processo de atribuição de causalidade: Problemas e perspectivas. Reflexão e Crítica, v. 3, p. 49-59, 1988.

REID, G. Motivating learners in the classroom: ideas and strategies. Londres: Paul Chapman Publishing, 2007.

RODRIGUES, A. Atribuição de causalidade e avaliação de resultados: Uma comparação transcultural. Arquivos Brasileiros de Psicologia, v. 32, p. 137-147, 1980.

RODRIGUES, A. Atribuição de causalidade: estudos brasileiros. Arquivos Brasileiros de Psicologia, v. 36, n. 2, p. 5-20, 1984.

ROSS, M.; FLETCHER, G. Attribution and social perception. In: LINDSAY, G.; ARONSON, E. (orgs.). Handbook of social psychology. 3. ed. Nova York: Lawrence Erlbaum Associates, 1985. v. 2.p. 73-122.

ROTTER, J. B. Generalized expectancies for internal versus external control of reinforcement. Psychological Monographs, v. 80, n. 1, p. 1-28, 1966. https://psycnet. apa.org/doi/10.1037/h0092976

RUSSELL, D. The causal dimension scale: a measure of how individuals perceive causes. Journal of Personality and Social Psychology, v. 42, n. 6, p. 1137-1145, 1982. http:// doi.org/10.1037/0022-3514.42.6.1137

RUSSELL, D.; MCAULEY, E. Causal attributions, causal dimensions, and affective reactions to success and failure. Journal of Personality and Social Psychology, v. 50, n. 6, p. 1174-1185, 1986. https://psycnet.apa.org/doi/10.1037/0022-3514.50.6.1174 SCHUNK, D. H.; PAJARES, F. Self-efficacy theory. In: WENTZEL, K. R.; WIGFIELD, A. (orgs.). Handbook of Motivation in School. Nova York: Routledge, 2009. p. 35-55.

SOUSA, E. Atribuição: da inferência à estratégia de comportamento. In: VALA, J.; MONTEIRO, M. (orgs.). Psicologia Social. 2. ed. Lisboa: Fundação Calouste Gulbenkian, 1996. p. 141-165. 
VALA, J. O que há de novo num texto velho - a propósito do artigo de Heider: "Social perception and phenomenal causality". Psicologia, v. 8, n. 1, p. 157-159, 1991. https:// doi.org/10.17575/rpsicol.v8i1.723

VALLERAND, R. J. Antecedents of self-related affects in sport: Preliminary evidence on the intuitive-reflective appraisal model. Journal of Sport Psychology, v. 9, n. 2, p. 161-182, 1987.

WEINER, B. A theory of motivation for some classroom experiences. Journal of Educational Psychology, v. 71, n. 1, p. 3-25, 1979.

WEINER, B. An attributional theory of achievement motivation and emotion. Psychology Review, v. 92, n. 4, p. 548-573, 1985.

WEINER, B. An attributional theory of motivation and emotion. Nova York: Springer-Verlag, 1986.

WEINER, B. Human motivation: metaphors, theories and research. 2. ed. Newbury Park: Sage Publications, 1992.

WEINER, B.; FRIEZE, I. H.; KUKLA, A.; REED, L.; REST, S.; ROSENBAUM, R. M. Perceiving the causes of success and failure. In: JONES, E. E.; KANOUSE, D. E.; KELLEY, H. H.; NISBETT, R. E.; VALINS, S.; WEINER, B. (orgs.). Attribution: Perceiving the causes of behaviour. Morristown: General Learning Press, 1971.p. 95-120. WEINER, B.; KUKLA, A. An attributional analysis of achievement motivation. Journal of Personality and Social Psychology, v. 15, n. 1, p. 1-20, 1970. https://psycnet. apa.org/doi/10.1037/h0029211

WEINER, B.; RUSSELL, D.; LERMAN, D. Affective consequences of causal ascriptions. In: HARVEY, J. H.; ICKES, W. J.; KILDD, R. F. (orgs.). New directions in attribution. 2. ed. Hillsdale: Erlbaum, 1978.

\section{SOBRE O AUTOR}

Marco Ferreira é doutor em psicologia pela Universidade de Coimbra (Portugal). Professor do Instituto Superior de Educação de Lisboa (Portugal). E-mail: marco.ferreira@iseclisboa.pt

Recebido em $1^{\circ}$ de fevereiro de 2019 Aprovado em 29 de abril de 2019 